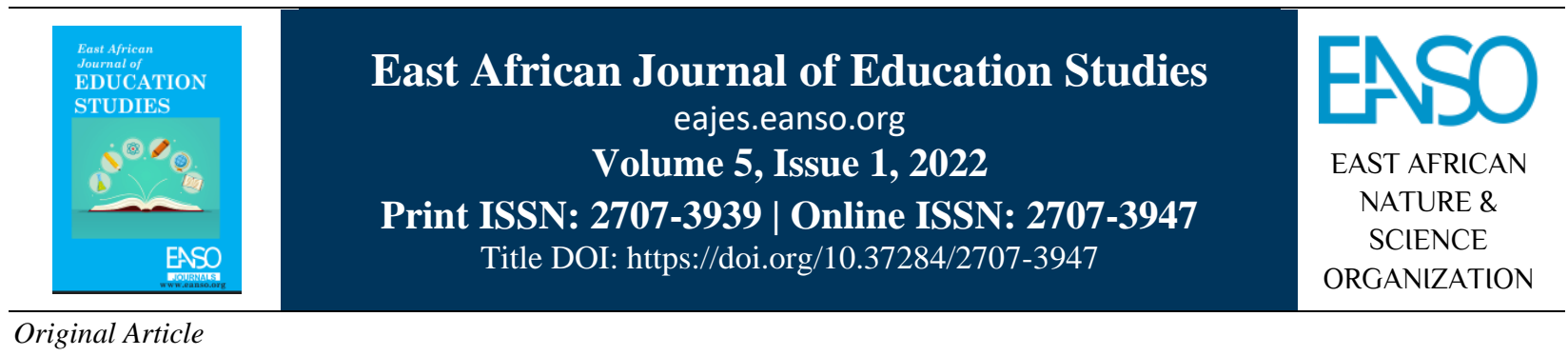

\title{
Teachers' Beliefs and Practices in Reaching Children's Varied Needs in Early Childhood Education Programs.
}

\author{
Tesema Regassa ${ }^{1 *}$, Prof. Belay Tefera, PhD ${ }^{2}$ Associate Prof. Dawit Negassa ${ }^{1}$, PhD \& Associoate \\ Prof. Firdissa Jebessa, $P h D^{2}$ \\ ${ }^{1}$ Haramaya University, P. O. Box 138, Dire Dawa, Ethiopia. \\ ${ }^{2}$ Addis Ababa University, P. O. Box 1176, Addis Ababa University, Ethiopia. \\ *Author for Correspondence Email: tsmrgs@gmail.com.
}

Article DOI: https://doi.org/10.37284/eajes.5.1.543

\section{Date Published: ABSTRACT}

04 February 2022 Quite a lot of research investigations were carried out in Ethiopia to

Keywords: examine ECCE designs, provisions, and contributions. However, little research was done to understand how developmentally appropriate were the

Developmentally Appropriate Practices, Early Childhood Care

Education,

Teachers' Beliefs,

Practices,

Children With Varied

Needs. ECCE designs and provisions. This research piece attempted to fill in this gap by attempting to explore teachers' beliefs and practices about reaching out for children's varied needs in Early Childhood Education programs in Adama Town. A sequential exploratory mixed design was employed in which data were collected through unstructured interviews, observation, and document analysis from purposefully selected private, government, and faith-based early childhood education centres. The participants of the study were 9 early childhood care and education (ECCE) teachers purposefully selected from private, faith-based, and government preschools. Data collected from a sample of nine teachers through interviews, records, and observation field notes were transcribed, coded, categorised, and developed into themes within and across cases. Data from the quantitative strand employed a sample of 190 (45\%) teachers from the three settings. The findings were presented under one overarching theme that revealed that children with special needs were minimally integrated into the ECCE settings. Also, the teachers had inadequate training and pedagogical skills to create inclusive ECCE settings for children with special needs. Moreover, environmental factors had a greater impact on their classroom practices than their beliefs. In discussions of their beliefs, the teachers mentioned various sources of barriers, such as limited knowledge and pedagogical skills, pre-service and in-service training, DAP curriculum, hands-on experience teaching materials, play equipment, suitable learning

37 | This work is licensed under a Creative Commons Attribution 4.0 International License. 
environment, budget, awareness about children with special needs and stakeholders' collaboration, which affected their practices. Lastly, the implications of this study for the ECCE stakeholders were suggested.

\section{APA CITATION}

Regassa, T., Tefera, B., Negassa, D., \& Jebessa, F. (2022). Teachers' Beliefs and Practices in Reaching Children's Varied Needs in Early Childhood Education Programs. East African Journal of Education Studies, 5(1), 37-53. https://doi.org/10.37284/eajes.5.1.543.

\section{CHICAGO CITATION}

Regassa, Tesema, Belay Tefera, Dawit Negassa, and Firdissa Jebessa. 2022. "Teachers' Beliefs and Practices in Reaching Children's Varied Needs in Early Childhood Education Programs". East African Journal of Education Studies 5 (1), 37-53. https://doi.org/10.37284/eajes.5.1.543.

\section{HARVARD CITATION}

Regassa, T., Tefera, B., Negassa, D., \& Jebessa, F. (2022) “Teachers' Beliefs and Practices in Reaching Children's Varied Needs in Early Childhood Education Programs", East African Journal of Education Studies, 5(1), pp. 37-53. doi: 10.37284/eajes.5.1.543.

\section{IEEE CITATION}

T. Regassa, B. Tefera, D. Negassa, \& F. Jebessa, “Teachers' Beliefs and Practices in Reaching Children's Varied Needs in Early Childhood Education Programs”, EAJES, vol. 5, no. 1, pp. 37-53, Feb. 2022.

\section{MLA CITATION}

Regassa, Tesema, Belay Tefera, Dawit Negassa, and Firdissa Jebessa. "Teachers' Beliefs and Practices in Reaching Children's Varied Needs in Early Childhood Education Programs”. East African Journal of Education Studies, Vol. 5, no. 1, Feb. 2022, pp. 37-53, doi:10.37284/eajes.5.1.543.

\section{INTRODUCTION}

In a survey conducted in a cluster of schools with mainstreaming of disabled students in Ethiopia, 93.5\% of the disabled students reported difficulty with gaining support from their parents, teachers, and peers (Dagnew, 2013). As many school-aged children are kept in the confines of their homes rather than brought to schools (MoE and UNESCO, 2012), working with parents in getting disabled children into classrooms, and providing them support while there, is important. A number of factors could be involved in their refusal (or inability) to enrol them in school, including the stigma which is attached to parents of children with disabilities, lack of community support, the inability of mainstream schools to include them, or distance from schools who offer inclusion for disabled children (Lewis, 2009).

The UNESCO article presented in 2006 stated that children who participated in Early Childhood Care and Education (ECCE) programs have

demonstrated improvement in school readiness, are more likely to enrol in first grade, and have lower rates of delayed enrolment, dropout, and grade repetition and increased completion and achievement. "Early childhood sets the foundations for life" (UNESCO, 2006a, p. 7). Despite the benefits of early childhood education, Ethiopia's "government has very limited intervention in this critical stage of education. The point is that preschool education in Ethiopia is not compulsory and neither is any budget allotted by the government for it" (Woldehanna, 2011, p. 116).

The National Ethiopian government, with the supp -ort of UNICEF drafted a strategic operational plan and Guidelines for Early Childhood Care and Education and National Policy Framework for Early Childhood Care and Education (MoE, 2010). Access to early childhood education has been growing over the years. Currently, government, private owners, NGOs, communities, and religious organisations are running ' $\mathrm{O}$ ' class, child to child and kindergarten programs and playing their part in educating children. Major challenges of the Ethiopian ECE are environment and physical space, curriculum content and pedagogy, early childhood educators and caregivers, partnership with families and communities, and access to young children with special needs (Admas, 2017).

Inclusive early childhood settings are those settings that recognise that all children and their families have the right to access quality education and care 
from settings of their choice regardless of their gender, culture, ability, disability, or any difference (Education Review Office, 2012). In inclusive settings, teachers promote equity and social justice and strive to give children and their families a sense of belonging while the individual needs of children are met (Moffat, 2011). To achieve this, teachers must be aware of dominant assumptions, beliefs, attitudes, and exclusionary practices so that they can challenge these when advocating for children's rights. There is no doubt that even with environmental philosophies and policies that are inclusive to all children, settings will not be inclusive without effective teachers. Their dedication plays a big part in meeting individual needs (Foreman, 2011). However, some teachers may have negative attitudes towards children with diverse needs (Macartney \& Morton, 2013; Neilson, 2005) and make it difficult to meet individual needs.

Developmentally appropriate practices (DAP) are methods that promote each child's optimal development and learning through a strengthsbased, play-based approach to joyful, engaged learning. Educators implement developmentally appropriate practice by recognising the multiple assets all young children bring to the early learning program as unique individuals and as members of families and communities. Building on each child's strengths and taking care to not harm any aspect of each child's physical, cognitive, social, or emotional wellbeing, educators design and implement learning environments to help all children achieve their full potential across all domains of development and across all content areas. Developmentally appropriate practice recognises and supports each individual as a valued member of the learning community. As a result, to be developmentally appropriate, practices must also be culturally, linguistically, and ability appropriate for each child (NAEYC, 2020).

Educators incorporate and integrate a wide variety of experiences, materials, equipment, and teaching strategies to accommodate the range of children's individual differences in development, languages, skills and abilities, prior experiences, needs, and interests. Educators are prepared to individualise their teaching strategies to meet the specific needs of individual children, including children with disabilities and children whose learning is advanced, by building upon their interests, knowledge, and skills. Educators use all the strategies identified here and consult with appropriate specialists and the child's family; they see that each child gets the adaptations and specialised services needed for full inclusion as a member of the community and that no child is penalised for their ability status (Copple \& Bredekamp, 2009; Hart et al., 1997).

The integration of children with and without disabilities is relatively new to early childhood education (Allen \& Cowdery, 2011). However, these days, there is a need for children with special needs to be part of the regular preschool education system. If children with special needs are part of the education system, they may then receive quality education services from the preschools they are attending. In general, children with special needs have no equal access in preschools (Fantahun, 2013). Likewise, educators (teachers) have a key role in sharing the day-to-day education and care of the young child with the parents. The partnership requires mutual, continuous, and committed interaction in all matters concerning the child. ECE partnership is built on the child's needs, the realisation of the child's best interests and rights being the guiding principle in all ECEC activities (Stakes, 2004). ECE partnership combines the knowledge and experiences of parents and ECE staff, both of which are important influences in the child's life. Some parents have mistaken beliefs that a difficult and academic-oriented curriculum is good for very young children and promote the sharing of responsibilities for children's development and learning. Inclusive schools must recognise and respond to the diverse needs of their students, accommodating both different styles and rates of learning and ensuring quality education to all through appropriate curricula, organisational arrangements, teaching strategies, resource use and partnerships with their communities. While the fun damental principal of the inclusive school is that all children should learn together, wherever possible, regardless of any difficulties or differences they may have. There should be a continuum of support and services to match the continuum of special needs education encountered in every school (Armstrong et al., 2011). 
This study attempts to examine teachers' beliefs and practices of endeavouring the varied needs of child -ren with special needs through developmentally appropriate practices (DAP) which refers to the child-centred approach to instruction that views the child as the primary source of the curriculum and recognizes young children's unique characteristics. and is important for several reasons. First, no investigation has been conducted about teachers' beliefs and practices in reaching children's varied needs in Early Childhood Education Programs for ECCE teachers in Adama Town. This study may be adding a contribution to the study of this topic. Second, to describe the status of teachers' beliefs and practices about a dimension of DAP, in addressing the unique individual interests of children. Third, there is a need to identify the environmental factors that affect their practice for classroom instruction. Results of the study should be useful for policymakers and practitioners in the field in Adama to inform decisions about ECCE in the region. The following questions guided the study:

- How do ECCE teachers describe their beliefs and practice regarding children with special needs in private, faith-based, and government centres?

- To what extent are the teachers' self-reported beliefs and practices address the situation of children with special needs?

- Are there differences among ECCE teachers in the private, government, and faith-based centres with respect to beliefs about and practices of developmentally appropriate practices in addressing the situation of children with special needs?

\section{METHODS}

This study used a sequential exploratory mixed research design, where qualitative data were collected and analysed in the first phase and quantitative data were collected and analysed in the second phase sequentially. The multiple case studies were designed appropriately for the qualitative research as it can enable a greater understanding of how ECCE teachers describe their beliefs and practice regarding developmentally appropriate teaching practices for children learning and development regarding children with special needs in private, government, and faith-based centres in Adama Town.

The second phase of quantitative data collection was achieved using a Likert scale questionnaire. A survey research design was used to describe the status of ECCE teachers' beliefs and practices about DAP in the private, government, and faith-based centres. It consisted of two scales, namely the Teachers Beliefs Scale (TBS) measuring teachers' teaching beliefs and Instructional Activities Scale (IAS) measuring teachers' teaching practices.

\section{Participants}

From each of the three types of ECE centres: privat e, faith-based, and government, A total of nine (9) preschool teachers were selected purposively as depicted in Table 1 below. The criteria used for selecting the study participants included voluntary participation and consent having at least qualification of Certificate in ECCE, availability of children with special needs in the classroom, and.

Table 1: Participant's demography

\begin{tabular}{|c|c|c|c|c|c|c|c|c|}
\hline \multirow[t]{2}{*}{$\begin{array}{l}\text { Type of } \\
\text { Centre }\end{array}$} & \multirow[t]{2}{*}{$\begin{array}{l}\text { Number of } \\
\text { centres }\end{array}$} & \multicolumn{4}{|c|}{ Teachers } & \multicolumn{2}{|c|}{$\begin{array}{l}\text { Assistant } \\
\text { teachers }\end{array}$} & \multirow[t]{2}{*}{$\begin{array}{l}\text { No. of } \\
\text { children }\end{array}$} \\
\hline & & No & Sex & Age & Experience & Qual & & \\
\hline \multirow[t]{3}{*}{ Private } & 3 & 1 & $\mathrm{~F}$ & 35 & 12 & Cert & Yes & 41 \\
\hline & & 1 & $\mathrm{~F}$ & 28 & 6 & Cert & Yes & 43 \\
\hline & & 1 & $\mathrm{~F}$ & 51 & 25 & Cert & Yes & 55 \\
\hline \multirow[t]{3}{*}{ Faith based } & 3 & 1 & $\mathrm{~F}$ & 50 & 21 & Cert & Yes & 40 \\
\hline & & 1 & $\mathrm{~F}$ & 40 & 8 & Cert & No & 45 \\
\hline & & 1 & $\mathrm{~F}$ & 33 & 9 & Cert & Yes & 40 \\
\hline
\end{tabular}

40 This work is licensed under a Creative Commons Attribution 4.0 International License. 
East African Journal of Education Studies, Volume 5, Issue 1, 2022

Article DOI: https://doi.org/10.37284/eajes.5.1.543

\begin{tabular}{|c|c|c|c|c|c|c|c|c|}
\hline \multirow[t]{2}{*}{$\begin{array}{l}\text { Type } \\
\text { Centre }\end{array}$} & \multirow[t]{2}{*}{$\begin{array}{l}\text { Number of } \\
\text { centres }\end{array}$} & \multicolumn{4}{|c|}{ Teachers } & \multicolumn{2}{|c|}{$\begin{array}{l}\text { Assistant } \\
\text { teachers }\end{array}$} & \multirow[t]{2}{*}{$\begin{array}{l}\text { No. of } \\
\text { children }\end{array}$} \\
\hline & & No & Sex & Age & Experience & Qual & & \\
\hline \multirow[t]{3}{*}{ Government } & 3 & 1 & $\bar{F}$ & 22 & 3 & Cert & No & 66 \\
\hline & & 1 & $\mathrm{~F}$ & 23 & 3 & Cert & No & 45 \\
\hline & & 1 & $\mathrm{~F}$ & 24 & 3 & Cert & No & 52 \\
\hline
\end{tabular}

Source: Adama Education Office, Cert = Certificate

For the quantitative strand of the study, a sample consisting of $190(45 \%)$ preschool teachers was selected out of a total of 425 using the proportionate stratified random sampling technique from the

private, government, and faith-based settings. The strata were formed based on the type of ECCE centres, as shown in Table 2 below.

Table 2: Description of the Population and Samples

\begin{tabular}{llllll}
\hline Type of Preschool & \multicolumn{3}{l}{ Teachers/educators } & & \\
\cline { 2 - 5 } & \multicolumn{2}{l}{ Population } & Sample & N \\
\cline { 2 - 5 } & M & F & M & F & \\
\hline Private & 10 & 190 & 10 & 70 & 80 \\
Faith based & 10 & 115 & 10 & 50 & 60 \\
Government & 10 & 90 & 10 & 40 & 50 \\
Total & 30 & 395 & 30 & 160 & 190 \\
\hline
\end{tabular}

\section{Data Collection Instrument}

Qualitative tools: The data were collected through unstructured interviews, nonparticipant observation , and document review to ensure triangulation. In line with this, the interview would be held with nine ECCE teachers, from each three private, three faithbased, and three government ECCE centres were included by purposive sampling technique, those who were key informants and active participants in the area of inquiry included in the sample. Document collection entails scrutiny of relevant documents, which could be a valuable source of information from ECCE centres and education offices that would be triangulated to crosscheck the data obtained from informants. Lastly, nonparticipatory observation of indoor and outdoor activities was conducted in the selected ECCE centres.

Quantitative tool: a questionnaire was developed for collecting data on teachers' beliefs and practices of DAP. The first section of the questionnaire included general information such as ECCE teachers' age, years of experience, teacher's training, early childhood educational backgrounds, and their level of education, whereas the second section included the Teacher Beliefs Scale and Instructional Activities Scale. For the rest of the items in the Teacher Beliefs Scale (\#2 - \#29), teachers' personal beliefs about early childhood programs were measured. The teachers evaluated themselves against each item on a 5-point Likert scale with the following anchors: $1=$ not at all important, $2=$ not very important, $3=$ fairly important, $4=$ very important, and $5=$ extremely important. The items included both developmentally appropriate (17 items) and inappropriate (11 items) beliefs about ECCE practices. The questionnaire consisted of (50) items to measure the skills on the five dimensions of DAP (i.e., Developmentally Appropriate Practices Beliefs (DAPB), Developmentally Inappropriate Practices Beliefs (DIPB), Family Culture \& Inclusion (FCIB) DAP practice, and DIP practice) published by NAEYC (Bredekamp \& Copple, 1997).

Likewise, the Instructional Activities Scale for teachers focused on how frequently certain appropriate and inappropriate stated practices occur in their classrooms. Each item is to be measured on a 5-point Likert scale with the following anchors: 1 $=$ almost never (less than monthly), 2 = rarely (monthly), 3 = sometimes (weekly), $4=$ very often (2-4 times a week), and $5=$ regularly (daily). The 
descriptions included both developmentally appropriate (13 items) and inappropriate (9 items) practices for kindergartens. Scores from the questions describing inappropriate beliefs and practices were recorded in the analysis procedure, so the higher scores represent teachers' stronger beliefs about and practices of developmentally appropriate practices. The questionnaire was given to the teachers at convenient times.

The questionnaire was validated to operationalise the theoretical framework and measures teachers' developmentally appropriate and developmentally inappropriate beliefs and practices in a way that was adjusted to the ECCE teacher's context in Adama Town to make the questionnaire appropriate and meaningful to the respondents. The internal consistency of items was also checked through a pilot study.

The questionnaire was constructed in three stages: In stage one: the researchers reviewed the literature related to developmentally appropriate practices and selected those related to the previous dimensions and modified them to make them more meaningful and useful to the context of Adama Town. Burts et al. (2000) and Kim (2005) were particularly consulted to construct valid items. In stage two: The pools of items were subjected to expert reviews concerning content validity and cultural fairness. A panel of experts was asked to evaluate each item for its relevance, clarity, redundancy, appropriateness, and cultural fairness to establish the face and content validity of the instrument. Moreover, overall, suggestions were given to reject a few items, merge similar items, and avoid ambiguity. Based on this review, the researchers put a list of 50 items (28 items for Teachers Beliefs Scale, which have 3 subscales 11 items related to DAP, 11 items on DIP, and 6 FCI) and 22 items Instructional subscales, which have 2 subscales (13 items related to Developmentally Appropriate Practices Instructional Activities (DAPIA) and 9 items on Developmentally Inappropriate Practices Instructional Activities (DIPIA) as a primary version for the questionnaire. Stage three: Pilot study: To have psychometric indicators for the items of the primary version of the questionnaire, it was administered to a sample of (35) kindergarten teachers that were selected randomly from the study population (not included in the study sample). The results showed that the internal consistency of Cronbach's alpha coefficient was (0.881), (0.709), (0.776), (0.827), and (0.770) for DAPB, DIPB, FCIB, DAPIA, and DIPIA respectively, denoting strong internal consistency of the items within the subscales.

\section{Methods of Data Analysis}

In this study, data analysis techniques were explora tory sequential from both qualitative thematic) and quantitative (inferential) methods. The analysis of the qualitative data was started immediately after the first interview was conducted and all the record ed data were transcribed verbatim. Pseudonyms (like T1, T2, T3, etc.) were used not to expose the identities of the participants. The qualitative data $\mathrm{g}$ enerated through interviews, document analysis, and non-participatory observations were analysed by transcribing and coding the responses of the inf ormants and identifying central themes. In addition , the thematic analysis method was employed for it helps organize data into categories and identify, analyse and report patterns (themes) within the data. Moreover, the data were examined for releva nce and meaningfulness of Dependability, creditabi lity, transformability, and crosschecked by the rese archer to maintain trustworthiness.

The quantitative data were analysed by using SPSS software package version 22. Both descriptive and inferential statistics were employed to analyse the collected data. Descriptive and inferential statistics such as percentage, frequency, mean, correlation, and ANOVA were computed to describe the status and the nature of experiences in the five sub-scales that influence their beliefs and practice in private, government, and faith-based settings.

\section{RESULTS AND DISCUSSIONS}

The results and discussion of the study are presented in this episode. The study aimed to describe the participants' lived experiences and reflections on reaching children's varied needs and how their beliefs and convictions are put into teaching practice in private, government, and faith-based settings.

In line with this, there were some subthemes identified within the larger theme of teaching to enhance learning and development, but the intention 
of this paper focused on understanding and reaching children's varied needs in inclusive ECCE settings.

The total mean score of the private teacher sample for the FCI subscale was 18.96 (3.16) ( $\mathrm{SD}=3.41$, range $=12-26)$; for the government teachers sample the total mean score was $21.06(3.51)(\mathrm{SD}=2.22$, range $=17-26)$ and for the faith-based teacher sample the total mean score was 18.88 (3.15) ( $\mathrm{SD}=$ 3.85 , range $=11-26)($ see Table 3). The total scores gathered in the current study indicate that the beliefs on the values of family, culture, and inclusion mean scores of teachers in private, government, and faithbased were on the average point, which indicates that teachers had to hold both DAP and DIP beliefs. Nevertheless, teachers in the government group show that they were more tend to hold beliefs about FCI than the teachers in the private and faith-based group. This may be true because the government policy encourages family, culture, and inclusions of children with special needs, which means children in ECCE centres should learn according to their developmentally age-appropriate, individual interest, and socio-cultural context. In addition, the children could learn in their mother tongue according to their interests, even if there was a family influence on their children's interests and needs.

Table 3: Descriptions of the teachers' beliefs and instructional activities scales

\begin{tabular}{llllllllll}
\hline Type of ECCE & & N & M & M/item & SD & Min & Max & Skewness & Kurtosis \\
\hline Private & FCIB & 80 & 18.96 & 3.16 & 3.41 & 12 & 26 & -.061 & -.746 \\
Government & FCIB & 50 & 21.06 & 3.51 & 2.22 & 17 & 26 & .284 & -.239 \\
Faith-based & FCIB & 60 & 18.88 & 3.15 & 3.85 & 11 & 26 & -.162 & -.867 \\
\hline
\end{tabular}

There was no statistically significant correlation between FCI and DAPIA. However, the correlations between the DAPB and FCI for private teachers related to the positive dimensions of developmentally appropriate practices were statistically significant $\left(\mathrm{r}=.35^{* *}, \mathrm{p}=.01\right)$. The magnitude of the correlations between DAPB and FCIB was .35, that is, practically low correlation (Cohen, 1988). The correlation coefficient of .35 indicates these two factors share about $35 \%$ of the common variance.

In the government group, there was no statistical significance among DAPB, FCI and DAPIA to the positive dimensions of developmentally appropriate practices. In faith-based group, the correlations among the three factors (i.e., developmentally appropriate practice beliefs (DAPB), family, culture, and inclusion beliefs (FCIB), and developmentally appropriate practices instructional activities (DAPIA)) related to the positive dimensions of developmentally appropriate practices were not statistically significant for all factors except for that between DAPB and FCIB ( $\mathrm{r}$ $\left.=.53^{*} *, \mathrm{p}=.001\right)$. The magnitude of the correlations between DAPB and FCIB was .53, that is, practically moderate correlation (Cohen, 1988). The correlation coefficient of .53 indicates these two factors share about $53 \%$ of the common variance.

\section{Group Differences on Developmentally Appropriate Beliefs and Practices}

One-way ANOVAs were selected to examine differences between teachers' beliefs (TBS), stated practices, and (IAS) actual practices in relation to family, culture, and inclusion dimensions in private, government, and faith-based settings. There was a significant difference among type of ECCE in which teachers were working on teachers' beliefs and practice scale collectively: FCIB, $\mathrm{F}_{(2,187)}=7.70$, $\mathrm{p}<.001$ and DAP practice while DAPIA, $\mathrm{F}_{(2,187)}=$ $24.97, \mathrm{p}<.001$.

Table 4: One-way ANOVA of Developmentally Appropriate Beliefs and Practices in relation to FCI

\begin{tabular}{llllllll}
\hline Type of ECCE & SS & Df & MS & F & Sig. & $\mathbf{\eta}^{2}$ \\
\hline \multirow{3}{*}{ FCIB } & Between Groups & 167.59 & 2 & 83.79 & 7.70 & .001 & .076 \\
& Within Groups & 2035.89 & 187 & 10.89 & & & \\
& Total & 2203.48 & 189 & & & & \\
\hline
\end{tabular}

Note. $p<.05=$ statistically significant level.

43 This work is licensed under a Creative Commons Attribution 4.0 International License. 
These significant results were followed up using the Post hoc Games Howell unequal variance test, which indicated that there were significant differences between government and faith-based teachers in DAP beliefs and practice, the Government teachers have held higher FCI beliefs $(\mathrm{M}=21.06, \mathrm{SD}=2.22)$ and fewer DAP practice $(\mathrm{M}$ $=33.20, \mathrm{SD}=3.43)$ than the Faith-based teachers' beliefs $(\mathrm{M}=18.88, \mathrm{SD}=3.85)$ and DAP practice $(\mathrm{M}=39.43, \mathrm{SD}=5.85)$ as well as private teachers DAP practices $(\mathrm{M}=18.96, \mathrm{SD}=3.41)$. These findings indicate that teachers in government centres tended to hold FCI beliefs and fewer DAIA practices than did those teachers in both the faithbased and private centres.

Table 5: Post hoc analysis of variance by type of ECCE of respondents

\begin{tabular}{|c|c|c|c|c|c|c|c|}
\hline \multirow{2}{*}{$\begin{array}{l}\text { Dependent } \\
\text { Variable }\end{array}$} & \multirow{2}{*}{ (I) } & \multirow{2}{*}{$(\mathbf{J})$} & \multirow{2}{*}{ MD(I-J) } & \multirow{2}{*}{ SE } & \multirow{2}{*}{ Sig. } & \multicolumn{2}{|c|}{$95 \% \mathrm{CI}$} \\
\hline & & & & & & LB & UB \\
\hline \multirow{6}{*}{ FCIB } & \multirow{2}{*}{ Private } & Government & -2.10 & .49 & .000 & -3.27 & -.93 \\
\hline & & Faith based centre & .08 & .63 & .991 & -1.41 & 1.57 \\
\hline & \multirow[t]{2}{*}{ Government } & Private & 2.10 & .49 & .000 & .93 & 3.27 \\
\hline & & Faith-based centre & 2.18 & .59 & .001 & .78 & 3.58 \\
\hline & \multirow[t]{2}{*}{ Faith-based centre } & Private & -.08 & .63 & .991 & -1.57 & 1.41 \\
\hline & & Government & -2.18 & .59 & .001 & -3.58 & -.78 \\
\hline
\end{tabular}

Note. $p<.05=$ statistically significant level.

\section{Discussion}

The present study has two major purposes. The first was to describe the status of ECCE teachers' beliefs and practices about DAP regarding children with special needs in the private, government, and faithbased centres. The second was to examine the differences among the private, government, and faith-based ECCE teachers on developmentally appropriate beliefs and practices focusing on children with special needs

\section{Understanding and Reaching Children with varied Need}

Recognising and meeting all children's varied needs would be very essential for teachers in understanding the individual needs of children to scaffold in their learning and development according to their needs and interest. All the informants reflected that the teachers had limited knowledge and skills about the unique individual interest on how to plan, implement and assess to meet their individual needs of children learning and development. As they noticed that this dimension of DAP was the most neglected part in private, faithbased and government ECCE centres.

The informants noticed that teachers were limited awareness, knowledge, and pedagogical skills on how to intervene with children with special needs according to their needs and interest in an inclusive setting in private, faith-based, and government ECCE centres. In addition, they were lacking in how to plan, implement and evaluate individualised educational plans (IEP) for children with special needs learning and development. Even they did not identify, organise, accommodate and group to support children with special needs according to their needs and interest. This result is supported by (Smith, 2010).

PT2 stated:

Our schedule is fixed and provided for all of us the same program at the beginning of the year. We are planning how to implement all the activities through the year according to the preplanned schedule in our centre. We have the same annual and weekly lesson plan for all children learning and development according to our curriculum". I'm a little bit flexible according to the children's interests and classroom situations during the implementation of the curriculum.

In private centres, the informants indicated that they did not pay attention to children with special needs learning and development because they were giving priority to children whose parents afforded to pay 
the fee for their learning and development. Even they said that this was the mandate of the government to access the opportunities for children with special needs in ECCE centres, the education officials in our town did also not pay attention to children. With special needs learning and development in ECCE centre. These indicate that there was little awareness about children with special needs learning and development in a private ECCE setting. In contrast to this idea, the research findings also reflected by (Goldstein, 1997 p. 4).

PT3 said:

There are some children with physical disabilities in our centre who are learning with their peers. I think there is little support from our teachers for their learning and development because they may not have adequate training on how to support children with special needs for their learning and development. Even our centre could not pay attention to them. There is limited awareness regarding children with special needs education.

Similarly, faith-based centres teachers did not pay any attention to children with special needs learning and development; since there was a lack of awareness about children with special needs learning and development in an inclusive setting, the stakeholders lacked awareness. In addition, there were not assigned any experts who were responsible for the implementation of special needs education in our education office. Moreover, they had limited awareness, knowledge, and skills on how to plan, implement and evaluate to make the lesson meet the individual interest and needs for their learning and development. The previous research also confirmed that the planning of the teacher should aim to include the characteristics and needs of each child in the educational process (Taylor, 2007). To provide different activities to meet each child's specific needs and interests, the schedule should be flexible (Hart eta 1., 1997).

The entire teachers stated:

Children with educational needs are not included in our centre because they have their segregated place where children with disabilities can learn. Perhaps such type of program may need specially trained teachers and teaching materials to support them. We do not have any training on how to support children with special needs for their learning and development in an inclusive setting.

However, there was an inclusive ECCE centre in our town, which was opened by a faith-based Catholic Church. The setting was provided services for all children, including children with special needs in an inclusive setting. The centre has organised Montessori materials, interactive learning environment, hands-on experience learning materials, child-sized chairs, shelf, play equipment, and organised classroom arrangement for children learning and development, and sign language interpreter, warm, safe, secured, and attractive learning environment for children learning and development. On the contrary, most of the teachers working in the centre did not identify the types of children with special needs and provided an appropriate intervention for their children according to their needs and interest for their learning and development. This study reflected that teacher did not get adequate pre-service and in-service training on how to support children with special needs in an inclusive setting for their learning and development. The reasons for the limitation maybe their beliefs regarding the work with children (Kowalski et al., 2001; West, 2001), and maybe related to fewer professional development opportunities provided to the teachers (McMullen, 1999; Ray \& Smith, 2010).

On the other hand, most of the government ECCE centres did not have an accessible for children with special needs learning and development. In addition, the teachers had limited awareness about children with special needs how scaffolding in an inclusive setting for their learning and development, even the teachers had limited knowledge and pedagogical skills on how to support children in the classroom according to their unique individual needs and interest for their learning. Moreover, the informants indicated that they had a limited budget, teaching materials, play materials, and assistant teachers for children's learning and development. Some findings indicated that the reasons for the limitation may be related to fewer professional development opportunities provided to the teachers (McMullen, 1999; Ray \& Smith, 2010), and their beliefs regarding the work with children (Kowalski et al., 2001; West, 2001).

45 | This work is licensed under a Creative Commons Attribution 4.0 International License. 
The entire teachers stated:

We have some children with special needs in our classroom. We also tried to support them in the classroom through demonstrating, touching, gesture, and writing for them. Even the families are also lacking awareness on how those children could learn. Moreover, teachers had limited training on what, when, and how to teach children with special needs in an inclusive classroom according to their needs and interest. We think it may be good if the government should pay attention to deploying/or training special needs educators in ECCE centres to meet children's varied learning needs.

Nevertheless, there was one government ECCE centre that was supported by NGOs and served as an inclusive setting in the town. The informants noticed that the teachers had limited resources, knowledge, and pedagogical skills on how to plan, implement and assess the children learning according to their needs and interest. In addition, they indicated that they had a shortage of classrooms lack of trained special needs educators and assistant teachers to support the children according to their learning needs and interest. Even though the teachers were limited knowledge and pedagogical skills regarding children with special needs, they were trying their best to support the children through play, singing songs, small groups, whole groups, multisensory approaches, and handson experience for children learning, and developm ent. This result is supported by (Copple \& Bredeka mp, 2009).

GT3 said:

The annual and weekly lesson plan is fixed. It is not flexible according to the children's interests. Rather it focused on academic skills through repeating drills. It is also challenging to teach children with different age groups in the same classroom in an inclusive setting without an assistant teacher and inadequate training to support children with special needs according to their interests and needs.

GT3 explained further that:

Our centre has been an inclusive setting that provides services for children with special needs, including children without disabilities. We have some children with intellectual disability, autism, and physical disability included in our setting. However, some of the children with special needs have been staying for a long time in our centre until their age would be 11 and 12 years old, particularly children with intellectual disabilities. Because they did not have an alternative opportunity to continue their learning in neighbouring primary school, since there was no readiness from primary school to admit those children in an inclusive setting, and the parents were also requested us their children would stay here in our centre since they would not have an alternative opportunity for their children that provided services for their learning and development.

She thought that there was limited attention from the government for children with special needs to include in ECCE centres. Research findings were also described by Fantahun (2013). The researcher recognised that there was little integration of children with special needs in private, government, and faith-based centres. In addition, the teachers had limited knowledge and pedagogical skills on how to scaffold children with special needs according to their developmental characteristics, individual interest, and socio-cultural context in inclusive settings. Moreover, teachers had limited training on how to plan age-appropriate activities, organise learning materials and arrange the physical environment and individualised educational plans (IEP) for their learning and development according to their unique individual interests. Furthermore, some of the teachers were used to managing children's behaviour through external rewards such as reinforcement, threats, and punishments rather than managing by redirection, guidance, and problem-solving strategies. Furthermore, they used rigid schedules, materials, and activities with one right answer rather than open-ended activities for children divergent thinking. Lastly, some of them used primarily whole group lectures and discussion and individual seatwork rather than a variety of individual, small group, and whole-

group experiences. The literature also reflected on the issue by (Allen \& Cowdery, 2011).

However, in this town, there was only one government centre that provided services as an

46 This work is licensed under a Creative Commons Attribution 4.0 International License. 
inclusive setting for children with special needs in collaboration with NGOs. Also, there was one inclusive faith-based centre that had a comfortable learning environment, hands-on experience teaching materials, and a sign language interpreter for children learning and development. Those teachers who were working in the centres had also limited pre-service and in-service training on how to intervene in children with special needs in inclusive centres. Moreover, the stakeholders had limited awareness on how to include children with special needs in an inclusive setting and intervene according to their needs and interest in an inclusive setting. Furthermore, the government had lacked a structure in each education sector that would follow up the implementation and provide any appropriate support to them in an inclusive setting. Even the government did not assign any special needs experts to provide services to them and to facilitate the opportunities to access children with special needs to ECCE centres for their learning and development. The research findings also reflected on the issue by (Fantahun 2013).

Therefore, teachers in private, faith-based, and government centres had limited knowledge and skills on how to meet children where they are developmentally, how to address all children learning styles and how to manage children's behaviour in teaching appropriate skills. In addition, teachers had inadequate knowledge and pedagogic al skills on how to plan, implement and adapt the curriculum for children with special needs to intervene according to the unique individual interest and needs. Rather, teachers have used the traditional way of teaching approach through teachers-directed instruction in planning, implementing, and evaluati ng the same activities for the whole group. In addition, the teachers were used to managing their children's behaviour through reinforcement, rewarding, ignoring, and punishing them instead of facilitating an opportunity to solve their problem. In contrast to this idea some research described that the bases for planning and implementing these facets are children's individual differences (development al level, age, culture, gender, learning styles, intere sts, preferences, ideas, and socioeconomic backgro und) and individual needs (for mastery, independe nce, generosity and belonging) (Griebling, 2009; Morrison, 2011).

\section{Status of ECCE Teachers' Developmentally Appropriate Beliefs and Practices}

The teachers rated the values of family, culture, and inclusion as fairly important for private, governme nt and faith-based $(\mathrm{M}=3.16,3.51$, and 3.15

respectively). The government groups had higher values on FCI and DAPB than did on the country part of the private and faith-based groups. This finding may be due to the emphasis on inclusion in the government ECCE policy, whereas the private and faith-based are more follow their curriculum which focused on academic skills for primary school readiness. These results were comparable to the findings that emphasise multiculturalism and inclusion in the US, whereas students in Taiwan are more homogeneous in terms of ethnicity (Den Brok \& Levy, 2005).

The correlations among the three factors for private teachers (i.e., DAPB, FCIB, and DAPIA) related to the positive dimensions of developmentally appropriate practices were not statistically significant for all factors except for that between DAPB and FCIB factors. The magnitude of the correlations between DAPB and FCIB was .35, that is, practically low correlation (Cohen, 1988). Also, the correlations between the three positive and two negative dimensions were not statistically significant except for DIPB. Unexpectedly, DAPB was also significantly correlated with negative dimensions of DIPIA in the positive direction at .22. The correlation between DAPIA and the negative dimensions of DIPB were statistically significant in the positive direction at .23. This might be teachers did not get adequate pre-service and in-service training, lack of national curriculum, and limited pedagogical skills, particularly child-centred approach to understand properly about DAP beliefs and practice for children according to developmental characteristics, individual interest, and socio-cultural context. The second point might be due to the fact that teachers may be facing challenges due to environmental factors to practice their beliefs as needed, such as fragmented structure, large class size, limited resources, crowded learning environment, limited learning materials, and stakeholders support for children learning according to children developmental characteristics, individual interest, and sociocultural context. The research results indicate that 
several reasons stand behind this inconsistency such as physical environment, limited resources, crowded classrooms, lack of partnership between parents and teachers, and negative attitudes of others towards the profession (McMullen et al., 2005). Several authors contended that a discrepancy exists between teachers' beliefs and practices (e.g., Charlesworth, Hart, Burts, Mosley, \& Fleege, 1993; McCarty et al., 2001; Vartuli, 1999).

In the government group, there was no statistical significance among all factors except for the DAPB. DAPB was significantly correlated with negative dimensions of DIPB. The magnitude of the correlations between DAPB and DIPB was .38, that is, practically low correlation (Cohen, 1988). This might be due to the fact that the attributed characteristic of ECCE in a government setting. It was open attached to primary school, which was making the program as an extra activity, particularly; the school leader did not take the responsibility as main activities in their planning, implementing, and evaluating teaching-learning process. In addition, the centres had limited trained teachers, special needs educators, teaching materials, play materials, classrooms, and stakeholders' support. Research has shown that some contextual factors have an impact on the association between beliefs and practices and may affect teachers' classroom practices (e.g., class size) (Hedge \& Cassidy, 2009; Parker \& NeuharthPritchett, 2006; Phillips et al., 2000).

In the faith-based group, the results showed from the three positive dimensions only a moderate correlation between DAPB and FCIB in the positive direction at .53. The magnitude of the correlations between DAPB and FCIB was .53, that is, practically moderate correlation (Cohen, 1988). This might be due to the fact that even if teachers had inadequate training as the other centres, some of the centres had interactive learning environments, hands-on experience teaching materials, play materials, and facilities, particularly those supported by the Catholic church. Deniz (2004) posited that teachers' beliefs and practices are associated with the relevant context, in that; teachers might choose or decide upon specific beliefs when encountered by certain teaching situations before choosing a specific practice.

\section{Differences Among Private, Government and Faith-Based Centres}

The means and standard deviations indicated that there were differences among the means of teachers' beliefs and practices in private, faithbased, and government centres. To determine whether these differences were significant, ANOVA was used. The findings showed that there were statistically significant differences among type of ECCE: FCIB, $\mathrm{F}=7.70, \mathrm{p}<.001$, and DAPIA, $\mathrm{F}=$ 24.97, $\mathrm{p}<.001$. Results of Post hoc comparison Games Howell unequal variance test indicated that the differences between government and faith-based teachers' FCI beliefs and practice were significant, the government teachers have held higher FCI beliefs $(\mathrm{M}=21.06, \mathrm{SD}=2.22)$ and fewer DAP practice $(\mathrm{M}=33.20, \mathrm{SD}=3.43)$ than the Faithbased teacher's beliefs $(\mathrm{M}=18.88, \mathrm{SD}=3.85)$ and DAP practice $(\mathrm{M}=39.43, \mathrm{SD}=5.85)$ and did private teachers DAP practices $(\mathrm{M}=18.96, \mathrm{SD}=$ 3.41). This may be due to the less experience of teachers from the government centres and the more recent introduction of the child-centred approach. In addition, teachers in government centres had limited training, teaching materials, play equipment, facilities, budget, and stakeholders' support. Hence, teachers in government centres tended to hold FCI beliefs and fewer DAIA practices than did those teachers in both the faith-based and private centres. The research findings reported that teachers' selfreported practices and actual practices were less consistent with DAP than their beliefs. (Hegde and Cassidy 2009; McMullen et al., 2005; Rentzou \& Sakellariou, 2011). Moreover, teachers in government centres would have awareness about family, culture, and inclusive education and more exposure to the government ECCE policy, which has a positive effect on beliefs about FCI. Nevertheless, teachers in private centres more tend to focus on teaching academic skills than their counterparts. These results were comparable to the findings that emphasise multiculturalism and inclusion in the US, whereas students in Taiwan are more homogeneous in terms of ethnicity (Den Brok $\&$ Levy, 2005; Tirusew et al., 2009).

More specifically, the government ECCE teachers have stronger FCI beliefs and fewer DAPIA practices than the faith-based and private ECCE teachers. The faith-based teachers also report 
significantly more DAPIA activities in their classrooms than the government and private teachers. All of the government teachers similarly rated the value of the family, culture, and inclusions higher than private and faith-based teachers. This may be because teachers in government centres would have more awareness about family, culture, and inclusive education than their counterparts did in private and faith-based groups. In addition, teachers in government centres had access to more exposure to the government ECCE policy than their counterparts did in the two groups. The research findings are also reflected in contrast (Teffera et al., 2009).

Major Findings indicate that:

- There was little integration of children with special needs in private, government and faithbased ECCE centres.

- Teachers had limited knowledge and pedagogical skills in addressing the unique individual interest on how to plan, implement and assess to meet their individual needs of children learning and development. Thus, the unique individual interest dimension of DAP was the most neglected part in private, faithbased and government ECCE centres.

- The teachers in government and private settings also had a large class size; less furnished learning environment, limited pre-service training, inservice training, teaching materials, play materials, interactive learning environment, and stakeholders' support to endorse DAPIA, lack of trained school leaders and special needs educators to support children according to their interests and needs to endorse a child-centred approach.

- The teachers in private, government and faithbased centres may hold both FCI and DIP beliefs at an average level and endorse DAP activities sometimes in their classrooms. The teachers need improvement in their DAP beliefs and practice among the three settings to make the teaching-learning process in addressing children with special needs.

- Teachers in government centres would have awareness about family, culture, and inclusion of children with special needs and more exposure to the government ECCE policy, which has a positive effect on beliefs about FCI. Also, the children could learn in their mother tongue according to their interests in government settings, whereas the private and faith-based are more follow their curriculum which focused on academic skills for primary school readiness.

- Teachers in faith-based centres had relatively adequate physical environment, resources, inservice training, and hands-on experience materials, particularly ECCE centres run by the faith-based Catholic Church.

- Even though there were many limitations regarding the inclusion of children with special needs in ECCE settings, the beginning of inclusion in one government and one faith-based centre have to be encouraged and supported as a model in order to expand to other centres.

\section{Limitation}

There were several limitations to the current study. First, the generalizability of the results may be limited. For the study was restricted primarily to one urban city in Oromia regional state, which is Adama Town. All the urban cities in Oromia regional states have their sole characteristics. Second, the translate $\mathrm{d}$ survey did not demonstrate adequate psychometri c properties in private, government, and faith-based samples. Fourth, an indication of developmentally appropriate/inappropriate beliefs and practices was based on the self-reported questionnaires with limited response reliability, but there was support from the qualitative part for contextual validity from the dissertation conducted in the town. Third, only the researcher observed the classroom as a noneparticipator and there was no crosschecking between observers.

\section{CONCLUSION}

Recognising and meeting all children's varied needs would be very essential for teachers in understanding the unique individual needs of children to scaffold in their learning and development according to their needs and interest. However, teachers had limited knowledge and skills about the unique individual interest on how to plan, 
implement and assess to meet their individual needs of children learning and development. Also, the teachers were limited awareness, training, and skills on how to intervene with children with special needs according to their needs and interest in inclusive settings. Moreover, they were lacking in how to plan, implement and evaluate individualised educational plans (IEP) for children with special needs learning and development. Furthermore, teachers had limited knowledge about theories underpinning DAP and the pedagogical skills on how to plan IEP, organise, coordinate, and use child-centred teaching strategies for children learning and development through play-based using hands-on experience. Even they did not identify, organise, accommodate and group to support children with special needs according to their needs and interest. Hence, this dimension of DAP was the most neglected part in private, faith-based and government ECCE centres. Therefore, this is noteworthy if one wishes to improve classroom practices for all children so that the government, policymakers, experts, leaders, and teachers training colleges should be taking into account this issue for further improvement.

\section{The Implications of the Study}

Understanding how the teachers reach children's varied needs and the factors that impede the actual classroom practice in private, government and faithbased settings help to promote school leaders and teachers to plan best practices for young children. The following are some suggested implications that were derived from this study:

- School leaders and stakeholders should create awareness on the inclusion of children with special needs in ECCE settings;

- Teachers need continuous professional development regarding how to support children with special needs in ECCE inclusive settings;

- Pre-service and in-service training needs to be organised for teachers and school leaders regarding the inclusion of children with special needs in ECCE settings to promote children's social, emotional, creativity, cognitive and physical development;
- The governments should facilitate awareness, panel discussion, and discussion forums among stakeholders on the issue of including children with special needs in ECCE settings.

- The government need to structure each education sector in order to assign experts who are responsible for following the implementation of including children with special needs in ECCE settings.

\section{REFERENCES}

Aldridge, J., Emfinger, K., \& Martin, K. (2006). Curriculum frameworks, approaches, and models in early childhood education: What's the difference? Focus on Teacher Education, 7(2), 3-7.

Allen, E. K. \& Cowdery, G. E. (2011). The excepti onal child: Inclusion in early childhood education ( $5^{\text {th }}$ ed.). Wadsworth Publishing Company.

Allen, E. K. \&, Cowdery, G. E. (2011). The exceptional child: Inclusion in early childhood education, (5th ed.). Wadsworth Publishing Company.

Armstrong, D., Armstrong, A. C. \& Spandagou, I. (2011). Inclusion: by choice or by chance? International Journal of Inclusive Education, 15 (1), 29-39.

Bredekamp, S., \& Copple, C. (1997). Development ally appropriate practice in early childhood programs (Rev. ed). Washington, DC: National Association for the Education of Young Children.

Brown, C.P., \& Feger, B.S. (2010). Examining the challenges early childhood teacher candidates face in figuring their roles as early educators. Journal of Early Childhood Teacher Education, 31(4), 286- 306. doi:10.1080/10901027.2010.5 23774

Chan, W.L. (2016). The discrepancy between teachers" beliefs and practices: A study of kindergarten teachers in Hong Kong. Teacher Development, 20(3), 417-433. doi: $10.1080 / 13664530.2016 .1161658$

50 This work is licensed under a Creative Commons Attribution 4.0 International License. 
Charlesworth, R., Hart, C. H., Burts, D. C., Thomasson, R. H., Mosley, J., \& Fleege, P. O. (1993). Measuring the developmental appropriateness of kindergarten teachers' beliefs and practices. Early Childhood Research Quarterly, 8(3), 255-276.

Cohen, J. (1988). Statistical power analysis for the behavioral sciences (2nd ed.). Hillsdale, NJ: Erlbaum.

Copple, C. \& Bredekamp, S. (2009). Development ally Appropriate Practice in Early Childhood Programs Serving Children from Birth Through Age 8 (3rd ed). Washington, DC: NAEYC.

Creswell, J. W. (2012). Research design: qualitative, quantitative, and mixed methods approach. Fourth edition. Thousand Oaks, CA: Sage.

Dagnew, Asrat (2013) Factors affecting the implementation of inclusive education in primary schools of Bahir Dar town administ ration', Education Research Journal, vol. 3, no.3, pp. 59- 67 .

Den Brok, P., \& Levy, J. (2005). Teacher-student relationships in multicultural classes: Reviewing the past, preparing the future. International Journal of Educational Research, 43(1-2), 7288.

Education Review Office. (2012). Inclusion of children with special needs in early childhood services (December 2012). Wellington: New Zealand: New Zealand Government. https://ero.govt.nz/sites/default/files/202105/Inclusion-of-Children-with-Special-Needsin-Early-Childhood-Services.pdf, Wellington: New Zealand.

Fantahun, A. M. (2013). Quality of early childhood education, parental factors and cognitive ability of pre-school children: A Multilevel Analysis. Doctor Dissertation, Department of Special Needs Education, College of Education and Behavioural Studies, Addis Ababa University.

Admas, F. (2016). Early childhood education in Ethiopia: Present practices and future directions. The Ethiopian Journal of Education, 36(2), 41-72.

Foreman, P. (2011). Inclusion in action (3rd Edition). Melbourne, Vic.: Cengage Learning Australia.

Foreman, P. (2011). Inclusion in action (3rd Edition). Melbourne, Vic.: Cengage Learning Australia.

Garvis, S., Twigg, D., \& Pendergast, D. (2011). Breaking the negative cycle: The formation of self-efficacy beliefs in the arts, A focus on professional experience in pre-service teacher education. Australasian Journal, 36(2), 36-41.

Goldstein, L. S. (1997). Between a rock and a hard place in the primary grades: The challenge of providing developmentally appropriate early childhood education in an elementary school setting. Early Childhood Research Quarterly, 12, 3-27.

Griebling, S. (2009), November). Meeting developmental needs through the visual arts. Workshop presented at Ohio Art Educators Conference, Cleveland, $\mathrm{OH}$.

Hart, C. H., Burts, D. C., \& Charlesworth, R. (Eds.). (1997). Integrated curriculum and developmentally appropriate practice: Birth to age eight. Suny Press.

Hegde, A. V., \& Cassidy, D. J. (2009). Kindergarten teachers' perspectives on developmentally appropriate practices (DAP): A study conducted in Mumbai (India). Journal of Research in Childhood Education, 23(3), 367-381.

Heisner, M. J., \& Lederberg, A. R. (2011). The impact of child development associate training on the beliefs and practices of preschool teachers. Early Childhood Research Quarterly, 26(2), 227- 236.

doi:10.1016/j.ecresq.2010.09.003

Kowalski, K., Pretti-Frontczak, K., \& Johnson, L. (2001). Preschool teachers' beliefs concerning the importance of various developmental skills and abilities. Journal of Research in Childhood Education, 16(1), 5- 14. doi:10.1080/0256854 0109594970

51 This work is licensed under a Creative Commons Attribution 4.0 International License. 
Lewis, Ingrid (2009) Education for disabled people in Ethiopia and Rwanda, [Electronic ], Available: http://unesdoc.unesco.org/ima ges/0018/001865/186564e.pdf

Macartney, B., \& Morton, M. (2013). Kinds of participation: Teacher and special education perceptions and practices of 'inclusion in early childhood and primary school settings. International Journal of Inclusive Education, 17(8), 776-792.

McMullen, M., Elicker, J., Wang, J., Erdiller, Z., Lee, S. M., Lin, C. H., \& Sun, P. Y. (2005). Comparing beliefs about the appropriate practice among early childhood education and care professionals from the US, China, Taiwan, Korea and Turkey. Early childhood research quarterly, 20(4), 451-464.

McMullen, M. B. (1999). Characteristics of teachers who talk the DAP talk and walk the DAP walk. Journal of Research in Childhood Education, 13(2): 216-30.

Ministry of Education (MoE) (1994). The National Education and Training Policy, Addis Ababa, Ethiopia.

Ministry of Education (MoE), Ministry of Women Affairs (MoWA), \& Ministry of Health (MoH), (2010 a,). National policy framework for early childhood care and education (ECCE) in Ethiopia., Addis Ababa, Ethiopia.

Ministry of Education (MoE). (2010). National policy framework for early childhood care and education (ECCE) in Ethiopia. Addis Ababa, Ethiopia: Government of Ethiopia.

MoE, MoWA, \& MoH, (2010 b). Strategic operational plan for early childhood care and education (ECCE) in Ethiopia, Addis Ababa, Ethiopia.

MoE, MoWA, \& MoH, (2010 c). Guidelines for early childhood care and education (ECCE) in Ethiopia, Addis Ababa, Ethiopia.

Ministry of Education (MoE) (2012) Special Needs/Inclusive Education Strategy, Addis Ababa.
Moffat, T. K. (2011). Increasing the teacher rate of behaviour specific praise and its effect on a child with aggressive behaviour problems. Kairaranga, 12(1), 51-58.

Morrison, G. S. (2011). Early Childhood Educatio $n$ Today. Upper Saddle River, NJ: Merrill/Prentice Hall. [Google Scholar]

NAEYC. (2020). Developmentally appropriate practice in early childhood education programs serving children from birth through age 8. A position statement of the National Association for the Education of Young Children. Retrieved from http://www.naeyc.org/files/naeyc/file/posi tions/PSDAP.pdf

Neilson, W. G. (2005). Disability: Attitudes, history and discourses. In D. Fraser, R. Moltzen, \& K. Ryba (Eds.), Learners with Special Needs in Aotearoa New Zealand (3rd Edition) (pp. 9-21). Australia: Dunmore Press.

Nelson, R. (2000). Personal and environmental factors that influence early childhood teachers' practices. Journal of Instructional Psychology, 27(2), 95. Retrieved from https://search.proques t.com/openview/f132e18bc081d361b2eaf54a09 $56 \mathrm{e} 4 \mathrm{fd} / 1$ ?pq origsite $=\mathrm{gscholar} \& \mathrm{cbl}=2029838$

NICHD Early Child Care Research Network. (2006). Child care effect sizes for the NICHD study of early child care and youth development. American Psychologist, 61(2), 99-116. Retrieved from http://dx.doi.org/10.1037/0003066X.61.2.99

Parker, A., \& Neuharth-Prichett, S. (2006).

Developmentally appropriate practice in kindergarten: Factors shaping teacher beliefs and practice. Journal of Research in Childhood Education, 21(1), 65+. doi:10.1080/025685406 09594579

Phillips, D., Mekos, D., Scarr, S., McCartney, K., \& Abbott-Shim, M. (2000). Within and beyond the classroom door: Assessing quality in child care centers. Early Childhood Research Quarterly, 1 5(4), 475-496.

Ray, K., \& Smith, M. C. (2010). The kindergarten child: What teachers and administrators need to

52 This work is licensed under a Creative Commons Attribution 4.0 International License. 
know to promote academic success in all children. Early Childhood Education Journal, 38(1), 5-18.

Rentzou, K., \& Sakellariou, M. (2011). The quality of early childhood educators: Children's interaction in Greek child care centers. Early Childhood Education Journal, 38(5), 367-376.

Stakes (2004). National curriculum guidelines on e arly childhood education and care in Finland. Helsinki: Author.

Taylor, G. R. (2007). Trends in special education: Projections for the next decade. Edwin Mellen Press

Teffera T., Zewdie T., Teffera B., Hagos B. \& Ges esse D. (2009). Status of childhood care and education in Ethiopia. In Tirussew Tefera, Aklilu Dalelo, and Mekasha Kassaye (eds.), First International Conference on Educational Research for Development: Vol. I. (pp. 188223). Addis Ababa: Addis Ababa University Press.

United Nations Educational Scientific and Cultural Organization. (2006a). Education for all global monitoring report (EFA GMR) 2007, 1-405. https://unesdoc.unesco.org/ark:/48223/pf00001 47794.

United Nations Educational Scientific and Cultural Organization: International Bureau of Education . (2006b). Strong foundations: Early childhood care and education. http://unesdoc.unesco.org/i mages/0014/001471/147190e.pdf.

Vartuli, S. (1999). How early childhood teacher beliefs vary across grade level? Early childhood research quarterly, 14(4), 489-514.

Woldehanna, T. (2011). The effects of early ch ildhood education attendance on cognitive $\mathrm{d}$ evelopment: Evidence from urban Ethiopia. Ethiopian Journal of Economics, 20(1), 113- 64. https://pdfs.semanticscholar.org/33 d7/130c520d4307cc9df59cd1aea41c7dab8a 06.pdf. 